\title{
Is there any Operational Difference between Trait Self-Control and Domain-Specific Self-Control? Example of Oral Sex Behaviour and Psychological Well-Being
}

\author{
Sovetkina $\mathrm{E}^{1 *}$, Verplanken $\mathrm{B}^{1}$ and Weiss $\mathrm{M}^{2}$ \\ ${ }^{1}$ Department of Psychology, University of Bath, Claverton Down, UK \\ ${ }^{2}$ Department of Pharmacy and Pharmacology, University of Bath, Claverton Down, UK
}

*Corresponding author: Elena Sovetkina, Department of Psychology, University of

\section{Research Article}

Volume 3 Issue 4

Received Date: April 16, 2018

Published Date: May 19, 2018

Bath, Claverton Down, Bath BA2 7AY, UK, Tel: +447803343087; Email: elena.c.sovetkina@bath.edu

\section{Abstract}

Self-control is one of the essential components of self-regulation contributing to individual's success in many areas of behaviour. The present study aimed to investigate the differences in operation of trait self-control and domain-specific self-control (i.e. sexual restraint) as applied to oral sex behaviour and psychological well-being (PWB). 180 first year university students completed the online longitudinal survey on two time points, four months apart. Our results indicated that, while both types of self-control were important for engagement in oral sex in on cross-sectional level, only sexual self-control was found to have a longevity effect for this behaviour over time. The proposed functional difference between these two types of self-control was also evident in assessing PWB. Investigating relationship between trait and sexual self-controls and their effects on both sexual and non-sexual behaviour challenged the view on self-control as 'intact entity' in regulating any type of behaviour and provided the evidence supporting the view that the regulation of domainspecific behaviour may be more heavily based on domain-specific type of self-control. Findings from this study can be used to further inform intervention programmes aimed to facilitate sexual behaviour change.

Keywords: Oral sex; Trait self-Control; Sexual restraint; Young people

\section{Introduction}

Sexual behaviour is the important part of university campus life. Typically, it includes coital and non-coital sexual activities and individual's emotional responses to these activities. Quality of students' sexual experiences on campus often depends on their abilities to successfully regulate their sexual behaviour. Although extensively studied over the last two decades, self-regulation of sexual behaviour in the general population is still lacking certain clarity and coherence.

\section{Benefits of Behavioural Self-Regulation}

In modern psychology, self-regulation is normally understood as an individual's capacity to alter its 


\section{Psychology \& Psychological Research International Journal}

behaviour in order to adjust their actions to a broad range of situational and social demands [1].

From the theoretical perspective, behavioural selfregulation consists of four main components: clear behavioural standards, effective monitoring system, strength of self-control abilities and motivation to control behaviour [1-5]. Self-regulation behavioural mechanism reacts on tempting stimulus from the current indivudual's environment and adjusts the immediate impulsive responses in accordance to the accepted behavioural standards. The final appropriate behaviour elicits the positive emotional reactions that consequently contribute to the quality of individual's psychological well-being. Any discrepancy between the final behaviour and behavioural standards results in negative emotional reactions that indicate the presence of self-regulation failure which requires re-adjustment of behaviour [6].

As a result, individual's ability to self-control provides individual and society with many benefits. For individual, good capacity to self-control were found to contribute to their success in many areas of behaviour, including school and work success, task performance, popularity, mental health, psychological adjustment and good interpersonal relationships $[7,8]$. The evidence of benefits of high selfcontrol in various areas of human behaviour allowed researchers to suggest that self-control is a self-regulation 'all-purpose' tool [9].

\section{Individual and Situational Differences in Self- Control}

Decades of studying self-regulation in different domains of health-related behaviour revealed that individuals differ in their reasoned attitudes (standards) to restrain potentially problematic behaviour and in their impulsive reactions toward tempting stimuli (due to genetic endowment, differences in learning history and current need states) [10-12]. They can also differ in their general innate capacity to self-control their behaviour (trait self-control), as well as in their ability to exert trait self-control in tempting situations over particular domain-specific behaviour $[13,14]$. In terms of trait selfcontrol, it was found that some individuals possess a strong self-regulating ability consistently from early childhood through adulthood, whereas others demonstrate consistently less success in self- regulation through their lifetime [15]. It does imply that trait selfcontrol is a relatively stable personality characteristic.
Research on capacity of self-control suggests that the individual's ability to self-regulate may also depend on the momentarily availability of self-control resources (e.g. state self-control) which can be temporarily limited or exhausted as a result of performing other tasks (i.e. ego depletion), thereby reducing their ability to exert selfcontrol subsequently [3,16-23]. In addition, it was proposed that people who are generally good in selfcontrol (trait self-control), such as managing their money or meeting deadlines, also will be good in controlling their behaviour in other behavioural domains, for example in sexual behaviour. Trait self- control and sexual restraint, as domain-specific self-control, were found to be correlated and most likely to act simultaneously [9]. Although supported by findings from some studies, this suggestion was questioned by evidence from the most recent research, demonstrating that people with generally high trait self-control can fail to exercise self-control over different range of domain-specific behaviour, for example in eating or in sexual restraint [24-26]. So far, these failures were attributed to situational demand of behaviour, such as ego depletion, and to permissive attitudes to the tempting behaviour. The other interpretation of these findings may be in possibility that trait self-control (general ability to self-control) and domain-specific behavioural control may act differently under situational demands and for different types of domain specific behaviour [25].

The precise mechanism of concurrent operation of trait and domain specific self-controls in sexual behaviour has been hardly investigated yet. The functions of and the relationships between trait and domain-specific selfcontrols received relatively little attention in research literature, and the existing empirical evidence are mixed [22]. There is also no clarity if self-control appeared to be an intact entity or a collection of relatively independent self-regulation phenomenon correlated with each other.

\section{The Current Study}

The present study was set up to further investigate the similarities and differences in operating of different types of self-control in sexual behaviour.

As previous research revealed that trait self-control will contribute to the success in both, restraining sexual behaviour and improvement in psychological adjustment, in our study we choose to explore the first year university students' oral sex behaviour in conjunction with their psychological adjustment to the campus life. We believed 


\section{Psychology \& Psychological Research International Journal}

that this approach allows us to discriminate between the roles of trait and sexual self-control in these behaviours.

For the clarity of comparisons, we used a longitudinal design. Students' oral sex behaviour and psychological well-being were assessed on two time points within four months period. This allowed us to assess the persistence of hypothesised relationships over time, by repeating measurements with the same sample of respondents four months later. In addition, the assessment of change over time rather than on a single occasion allowed examination of the factors within environmental contexts which could support or inhibit the dynamic processes involved in real and perceived changes in PWB. A four month period was chosen to provide an opportunity for hypothesised changes in self-control and behaviour to take place, and to provide a baseline reference point consistent with that. In addition, it allowed to control for adjustment effects, given the fact that data collection at Time 1 was carried out after students entered the university (OctoberNovember 2012) and data collection at Time 2 was conducted after they were back at the university at the beginning of the new semester. Such approach to explore the differences between two types of self-control was never used before.

The current study consisted of two parts.

Investigating Relationship between Trait SelfControl and Sexual Restraint in Oral Sex Behaviour and Psychological Well-Being (PWB) on Cross-Sectional and Longitudinal Level

In Part 1, based on findings from the previous research, we did not predict any gender differences in trait and sexual self-control. As in earlier studies, we expected to find a high to moderate correlation between trait selfcontrol and sexual self-control on both time assessment points.

We also expected that on both cross-sectional and longitudinal levels trait and sexual self-controls will be significant predictors of students' engagement in oral sex but the link between engagement in oral sex and sexual self-control will be stronger than between engagement in oral sex and trait self-control. At this point, we have not enough information from research to predict where exactly will lay the difference between two types of selfcontrol in giving and receiving oral sex. We can only briefly hypothesise that this difference will exist.

Finally, based on previous research, we anticipated that students with higher level of trait self-control will demonstrate better psychological well-being over both assessment points. We foresaw that trait self-control will be a stronger predictor of psychological adjustment than sexual self-control.

\section{Clarifying the Role of Two Types of Self-Control in Oral Sex Behaviour and PWB, Accounting for the Link between Behaviour and Emotional Consequences of this Behaviour}

In Part 2, in order to further investigate relationship between trait self-control and sexual self-control on longitudinal level we introduced a third self-regulation variable, namely Regulatory Focus Orientation (RFO).

The reason for considering RFO in conjunction with self-control variables was that the concept of RFO provide self-regulation theory with the clear link between individual's behaviour and emotional consequences of this behaviour, in our case, between oral sex behaviour and individual's psychological well-being.

According to the classic theory of achievement motivation and regulation focus theory [27-30], each individual possess one of two main strategies for goal attainment. These strategies based on their regulatory focus orientation (RFO) which is stable individual characteristic formed by their subjective experience of success or failure in achieving goals.

Individuals with a subjective history of success in their previous experience approach to a new goal with feelings of pride which produce reactions that direct their behaviour to encourage the new task goal (i.e. promotion regulatory focus orientation). Their self-regulation is mainly concerned with advancement, aspiration and accomplishment using 'eagerness' means which involve ensuring 'hits'. Individuals with a subjective history of failure in their previous experience approach to a new goal with a feeling of shame which produce reactions that direct their behaviour to avoid the new task goal (i.e. prevention regulatory focus orientation). Their selfregulation is mainly concerned with protection, safety and responsibility using 'vigilance' means which involve ensuring 'correct rejections'.

Regulatory focus theory proposes that there is a 'natural fit' between promotion focus orientation and the use of eagerness means, and between prevention focus orientation and the use of vigilance means [30]. This 'fit' appears in how the individuals value the outcomes of behaviour (gains or losses) and how they evaluate their 


\section{Psychology \& Psychological Research International Journal}

decisions as better (use of correct means for each orientation). Any discrepancies between individuals' RFO and use of correct means in attaining goals are indicated by affective reactions (i.e. positive/negative emotions) $[31,32]$. The 'fit' effect has been shown to be independent of participants' moods. The results of Higgins Laboratory studies demonstrate that this difference in strategic orientation has important implications for decisionmaking and problem-solving, as well as for people's experiences while engaging in different activities in their lives. The implications of this distinction for well-being have received insufficient attention in the achievement literature and needs to be examined further.

In the current study, we used the regulatory focus theory for clarifying the role of two types of self-control in oral sex behaviour and PWB, controlling for gender. We predicted that trait self-control and RFO will be the stronger predictors of psychological adjustment than sexual self-control.

We were also looking if there will be any disparity between RFO and self-control variables in their impact on PWB on longitudinal level. Based on the previous research, we expected that RFO will be as much important predictor of PWB as trait self-control on longitudinal level. Finally, we expected to find some relationships between both types of self-control variables and RFO. Taken into considerations the results from previous research, we expected that trait self-control will correspond with both RFOs for females, whereas sexual self-control will correspond with both RFOs for males.

\section{Method}

\section{Participants and Procedure}

The current study used the data from the larger research aimed to assess the university students' sexual behaviour. Consent to conduct this study was issued by the principal investigator's university department Research Ethics Committee.

Participants were recruited by online advert on four UK universities' internal websites. This advert invited the first year university students to take part in The Student Psychological and Sexual Health (SPSH) Survey. The survey was completed by each participant online privately and anonymously. The unique personal identification number (PIN) was issued for each participant. To prevent multiple completions and monitor the response rate, every participant received their own written PIN, irrespective of whether they participated or not. This PIN was distributed in an e-mail by the principal investigator alongside with study information, participants' rights, consent form, and log on details. Before completing this survey, participants were informed that they are about to consent to participate in a longitudinal study that will seek further survey information after four months through a computer generated e-mail reminder online.

The distribution list of the sample respondents was created according to their PIN numbers. The systemgenerated e-mail reminder was issued to each participant at Time 2 period, asking them to complete the second part of the study online. Each student was able to do this by pressing the e-mail link which re-directed them to the second part of online survey.

At Time 1 (October-November), all participants completed socio-demographic questions and the online questionnaire assessing their sexual behaviour, selfcontrol and psychological well-being. At Time 2 (February-March), the participants completed a questionnaire which contained transition questions about perceived changes that occurred since Time 1, and once again completed the same online questionnaire to assess any objective changes in their self-control related to sexual behaviour and psychological well-being.

\section{Measures}

Self-regulation was assessed using two standardized measures.

The Brief Self-Control Scale (BSCS; Tangney, Baumeister \& Boone, 2004) was chosen to measure trait self-control (measured only at Time 1) [7]. This is the13items scale with items rated on a 5-point Likert scale where $1=n o t$ at all and 5=very much. The BSCS demonstrated good internal consistency ( $\alpha$ s ranging from .83-.85; Tangney et al, 2004) in research with college students and good internal consistency ( $\alpha$ s ranging from .83-.84; Quinne \& Fromme, 2010) in research with university students. In our study, the alpha coefficient was $.88[7]$.

Self-control as related to sexual behaviour was measured by the Sexual Restraint Questionnaire (SRQ) which examines the ability to restrain sexual behaviour within the context of the demands of daily life (measured at both Time 1 and Time 2). In the present study, 10-items 


\section{Psychology \& Psychological Research International Journal}

version of this questionnaire showed alpha coefficients of .84 and .88 , respectively [9].

Psychological well-being was assessed using PWBS-42 version of the Ryff's Scale of Psychological Well-Being (Ryff, 1985) (measured at both time points). Ryff's inventory consists of a series of statements reflecting the six areas of psychological well-being: Autonomy, Environmental Mastery, Personal Growth, Personal Relationship, Purpose in Life, and Self-Acceptance, rated on 6-point Likert scale from $1=$ strong disagree to $6=$ strong agree. The validity of the instrument has been tested previously on adults age 25 or older but not on traditional-aged college students. PWBS-42 version showed good internal consistency ( $\alpha$ s ranging from .81.83; Seifert, 2005). In the present study, the alpha coefficients for total 42-item PWBS were .84 (Time 1) and .85 (Time 2) [33,34].

Oral sex behaviour at Time 1 was assessed by asking questions about the participant's engagement in two types of oral sex: (a) giving oral sex to the partner and (b) receiving oral sex from the partner, with the range of answer such as "yes", "no" and "I did not give/receive oral sex yet". At Time 2 participants were asked if they engaged in giving or receiving oral sex since Time 1 . The number of oral/vaginal sex partners they had since Time 1 was measured by students choosing an answer from 0 (none) to 4 (more than 10).

Perceived changes in PWB and Sexual Life since Time 1 were assessed by two questions: 'Since you last answer the survey, how much did your PWB/sexual life changed?' rated on 7-point Likert scale ranging from -3(very much worse) to +3 (very much better). Regulatory orientation was assessed by Regulatory Focus Questionnaire (RFQ; Higgins et al, 2001) which contains two psychometrically distinct sub-scales, the Promotion sub-scale and the Preventive sub-scale, reflecting an individual sense of their history of promotion or prevention success in goal attainment, respectively. 11 items of this questionnaire were rated on 5-point Likert scale anchored by 1 (never or seldom/never true/certainly false) to 5 (very often/always/certainly true). Each of these scales exhibited good internal reliability $(\alpha=.73$ for the Promotion scale and $\alpha=.80$ for the Prevention scale; Higgins et al, 2001) [35].

The strength of participants' personal/religious beliefs was assessed by asking them to rate them from 0 (no personal/religious beliefs at all) to 6 (I have strong personal/religious beliefs).

\section{Analysis}

Cross-sectional analysis: Descriptive statistics were calculated in total and for each gender. Differences across gender were explored using t-tests.

The relationship between self-control variables (i.e. trait self-control and sexual sex-control) and oral sex behaviour was assessed by series on one-way ANOVA tests.

The relationships between self-control variables PWB were tested by the series of linear regression analyses (in total and for each gender).

Longitudinal analysis: The change in oral sex behaviour and PWB between the two times points was assessed by a series of paired-samples t-tests.

The relationship between self-control variables (i.e. trait self-control and sexual sex-control) and oral sex behaviour at Time 2 was assessed by series on one-way ANOVA tests.

Hierarchical multiple regressions were conducted to assess the importance of the most influential variables from cross-sectional analysis in predicting PWB over a four month period (in total and for each gender). Time 1 total PWB scores were entered into the equation as a first step of the analysis as these were expected to have the greatest explanatory power on the outcomes at Time 2 . Self-control variables (e.g. trait self-control and dispositional ability to restraint sexual behaviour) were entered as a second step, followed by sexual behaviour variables and regulatory focus orientation variable (e.g. promotive and preventive). The final step in the analysis added perceived change variables and personal beliefs into the equation, to assess whether they could add additional explanatory power to the model.

The same regression analyses were re-run adding RFO variable to the previous set of variables to explore the relationship between RFO and PWB at Time 2, accounting for the self-control variables and the other variables of importance from cross-sectional study. The relationship between RFO and self-regulation variables was tested by regressing self-regulation variables on predicting RFO. 


\section{Psychology \& Psychological Research International Journal}

The influence of RFO on PWB in relation to oral sex behaviour was examined separately for students who reported receiving/giving oral sex and for students who reported not receiving/giving oral sex since Time 1 . Participants were classified in terms of whether, compared to others, they were relatively more promotion oriented or relatively more prevention oriented based on the median split on the difference between their RFO Promotion and RFO Prevention scores. To test the prediction that PWB scores will be influenced by promotion RFO, we regressed RFO promotion/preventive scores on PWB scores at Time 2 (in total and for each gender).

In all analyses, results were judged to be nonsignificant (NS) if $p>.05$. Effect sizes (Hedges g) were considered to be large if above .80 , moderate if above .50 , small if above .20, but not to be meaningful if below 20 . Partial eta squared was used to calculate effect sizes in ANOVA analyses, which represents the amount of variance which is accounted for by the effect.

\section{Results}

\section{Part 1 Results}

Completed data on the two time points was collected for 180 participants (male $\mathrm{N}=57$ (31.7\%), female $\mathrm{N}=123$ (68.3\%); mean age at time $2=18.94$ years $(\mathrm{SD}=1.08$; range $18-22$ years old); $83 \%$ of the sample reported to be White Caucasian.
Genders Differences in Engagement in Oral Sex, SelfControl and PWB: From the frequency data obtained using the oral sex status, at Time $1,70 \%$ of males and $75 \%$ of females have already had experience in giving oral sex and $76 \%$ of males and $78 \%$ of females - in receiving oral sex. At Time 2, there was about a $20 \%$ and $27 \%$ increase in engagement in giving and receiving oral sex, respectively. At both time points, there was no statistically significant difference between genders in engagement in oral sex.

Although males score generally higher than females on trait self-control (TSC) scores, $(p=0.3)$, there was the effect of gender on sexual self-control score at Time 1 $\left(\mathrm{F}=4.26, \mathrm{p}=.04\right.$, eta ${ }^{2}=.02$ [small]) with males scoring significantly higher then females, but not at Time 2 . At Time 1, males reported to have significantly higher PWB scores than females $(\mathrm{t}=2.135, \mathrm{df}=178, \mathrm{p}=.03)$. Between Time 1 and Time 2, we found a statistically significant improvement in PWB scores in total $(\mathrm{t}(179)=-4.47$, $\mathrm{p}<.001)$ and for each gender $(\mathrm{t}(56)=-2.29, \mathrm{p}=.03$, for males, and $\mathrm{t}(122)=-3.84, \mathrm{p}<.001$, for females).

Although overall males demonstrated better PWB than female $(p=0.4)$ at Time 2, there was no significant difference in PWB scores between genders.

\section{Descriptives}

Means, SDs and Pearson correlations of self-control and PWB variables are presented in Table 1.

\begin{tabular}{|c|c|c|c|c|c|c|}
\hline Variables & $\mathbf{M}$ & $\mathbf{S D}$ & $\mathbf{2}$ & $\mathbf{3}$ & $\mathbf{4}$ & $\mathbf{5}$ \\
\hline 1. Trait self-control & 41.83 & 8.33 & $.49^{* *}$ & $.43^{* *}$ & $.43^{* *}$ & $.39^{* *}$ \\
\hline 2. T1 Sexual self-control & 36.57 & 8.65 & & $.75^{* *}$ & $.21^{* *}$ & $.16^{*}$ \\
\hline 3. T2 Sexual self-control & 36.71 & 8.34 & & & .14 & $.15^{*}$ \\
\hline 4. T1 PWB & 175.79 & 25.99 & & & & $.63^{* *}$ \\
\hline 5. T2 PWB & 182.81 & 26.61 & & & & \\
\hline
\end{tabular}

Note 1: $\mathrm{N}=180,{ }^{*} \mathrm{p}<.05 ;{ }^{* *} \mathrm{p}<.01$ and ${ }^{* * *} \mathrm{p}<.001$.

Table 1: Means, SDS and Pearson correlations of the study variables at Time 1 (T1) and Time 2 (T2).

Trait self-control significantly correlated with sexual self-control measured at both time points (medium correlation). There was a high significant correlation between sexual self-control at Time 1 and Time 2 . Whereas trait self-control showed a medium significant correlation with PWB at both time points, the correlations between sexual self-controls with Time 2 PWB was much weaker. The correlation between Time 2 sexual selfcontrol and Time 1 PWB was not significant.

\section{Self-Control and Engagement in Oral Sex}

The Role of Trait and Sexual Self-Control in Engagement in Oral Sex at Time 1

One-way ANOVA tests revealed that there was a significant difference in trait self-control (TSC) between students in relation to engagement in giving oral sex $(F(2,177)=5.08, p=.007)$. Post Hoc Tests showed that this difference was significant between students, who reported never having had oral sex before, and students, 


\section{Psychology \& Psychological Research International Journal}

who reported having had it ( $\mathrm{p}=.017)$. This difference was also significant for students, who reported never having had oral sex before, and students, who reported not having giving oral sex before $(\mathrm{p}=.007)$. Students, who have not had oral sex yet, showed the higher TSC score than both students, who have had oral sex, and students, who have had oral sex but have not given oral sex. Although there was no significant difference in TSC scores between students in relation to engagement in receiving oral sex $(\mathrm{p}=0.1)$, there was a difference in TSC scores between students, who have not had oral sex yet, and students, who received oral sex before $(\mathrm{p}=.04)$. Students, who reported receiving oral sex before, had significantly lower TSC scores in comparisons with other groups. Students, who never received oral sex before, demonstrated the highest TSC scores.

As far as sexual self-control (SSC) is concerned, we found a significant difference in SSC scores between students in relation to both giving and receiving oral sex $(\mathrm{F}(2,177)=9.59, \mathrm{p}<.001$ and $\mathrm{F}(2,177)=10.32, \mathrm{p}<.001)$. Post Hoc Analysis revealed that, in giving oral sex, these differences existed between students, who had not have oral sex yet, and students, who have had oral sex already $(p<.001)$ and between those who did not have oral sex yet and those who had not given oral sex yet $(p=.001)$. Students, who had not given oral sex yet, demonstrated a significantly higher SSC scores, whereas students, who had given oral sex, showed the lowest SSC scores. In receiving oral sex, these was also a difference in SSC between students, who had not have oral sex yet, and students, who have had it ( $\mathrm{p}<.001)$. Students, who have not received oral sex yet, showed a significantly higher level of SSC, whereas students, who have received oral sex, showed the lowest SSC scores.

The Role of Trait and Sexual Self-Control in Engagement in Oral Sex at Time 2

At Time 2, we found no difference in TSC scores between students, who have had given and who have had received oral sex since Time 1 , and students, who have not $(\mathrm{p}=0.3)$.

In comparison with TSC, there was a significant difference in SSC scores between students, who have given and who have received oral sex since Time 1 , and students, who have not $(\mathrm{F}(1,178)=21.13, \mathrm{p}<.001$ and $F(1,178)=11.05, p=.001$, respectively). Students, who reported not giving oral sex and not receiving oral sex since Time1, demonstrated a higher level of SSC scores than students, who reported to be engaged in oral sex.

\section{Self-Control and PWB}

The Role of Trait and Sexual Self-Controls and Students' Engagement in Sexual Behaviour their PWB at Time 1

The effect of two self-control variables and two sexual behaviour variables (i.e. number of oral/vaginal sex partners) on PWB at Time 1 was assessed by linear regression analysis. The total model was significant $\left(\mathrm{F}(2,230)=8.2, \mathrm{p}=.001, \mathrm{R}^{2}=.14\right)$, with summary effect of two self-control variables accounting for $14 \%$ of variation in PWB (trait self-control: $\beta=.44, t=5.92, p<.001$; sexual self-control: $\beta=.17, t=2.25, p=.03$ ).

As the main sample consisted mainly of females (70\%), we examined the effects of self-control variables on PWB for males and females separately.

For males, the model was significant $(\mathrm{F}(3,66)=18.42$, $\mathrm{p}<.001, \mathrm{R}^{2}=.40$ ) with two self-control variables in total accounting for $40 \%$ of variances in PWB (trait selfcontrol: $\beta=.52, t=5.44, p<.00$; sexual self-control: $\beta=.34, t=$ $3.45, p=.001$ ). For females, the model was also significant $\left(F(3,157)=3.16, p=.02, R^{2}=.08\right)$, with one self-control variable and one oral sex variable in total accounting for $8 \%$ of variances in PWB (trait self-control: $\beta=.29, \mathrm{t}=3.44$, $\mathrm{p}=.004$; the number of oral sex partners: $\beta=.48, \mathrm{t}=2.82$, $\mathrm{p}=.006$ ).

The patterns of results suggest that PWB for females was predicted by their TSC score and by the number of their oral sex partners. For males, both types of selfcontrol were significant predictors of their PWB score.

\section{The Role of Trait and Sexual Self-Control and Students' Engagement in Sexual Behaviour for their PWB at Time 2}

Table 2 presents Means, SDs and correlations of all variables at Time 2 .

\begin{tabular}{|c|c|c|c|c|c|c|c|c|c|c|}
\hline Variables and range & $\mathbf{M}$ & $\mathbf{S D}$ & $\mathbf{2}$ & $\mathbf{3}$ & $\mathbf{4}$ & $\mathbf{5}$ & $\mathbf{6}$ & $\mathbf{7}$ & $\mathbf{8}$ & $\mathbf{9}$ \\
\hline 1. SC & 41.83 & 8.33 & $.43^{* *}$ & $.39^{* *}$ & .06 & -.07 & -.02 & -.14 & .12 & .03 \\
\hline 2. T2SSC & 36.71 & 8.34 & & $.16^{* *}$ & -.07 & -.09 & -.26 & $-.48^{* *}$ & -.02 & .08 \\
\hline 3. T2PWB & 182.81 & 26.61 & & & $.32^{* *}$ & -.004 & .13 & .03 & .09 & $.37^{* *}$ \\
\hline
\end{tabular}




\section{Psychology \& Psychological Research International Journal}

\begin{tabular}{|c|c|c|c|c|c|c|c|c|c|c|}
\hline 4.Change PWB & .31 & 1.07 & & & & $.44^{* *}$ & $.16^{*}$ & .02 & -.05 & .07 \\
\hline 5.Changesex & .33 & 1.13 & & & & & $.26^{* *}$ & $.21^{* *}$ & .04 & $.18^{*}$ \\
\hline 6.Vagpartnrs & .82 & .67 & & & & & & $.71^{* *}$ & -.04 & $.15^{*}$ \\
\hline 7.0ralpartnes & .86 & .75 & & & & & & & .04 & .03 \\
\hline 8. Religious B & 1.53 & .92 & & & & & & & & .14 \\
\hline 9. Personal B & 3.31 & 1.09 & & & & & & & & \\
\hline
\end{tabular}

Note 1: SC=Trait Self-Control; t2SSC= Sexual Self-Control at Time 2; Change PWB=perceived change in PWB at Time2; Change sex= perceived change in sexual life at Time2; Vagpartnrs= how many vaginal sex partners since time1; Oralpartnrs=how many oral sex partners since time1; Religios B= to what extent have religious beliefs; Personal $B=$ to what extent have personal beliefs.

Note 2: $\mathrm{N}=180,{ }^{*} \mathrm{p}<.05 ;{ }^{* *} \mathrm{p}<.01$ and ${ }^{* * *} \mathrm{p}<.001$

Table 2: Means, SDs and correlations of the study variables.

Trait self-control and sexual self-control correlated significantly with each other and with total PWB at Time 2 , but not with perceived changes in PWB at time 2 . Sexual self-control significantly correlated with the number of oral sex partners since Time1, whereas the trait self-control did not. As expected, perceived changes in PWB (but not changes in sex life) at Time 2 correlated with the total PWB scores at Time2. While PWB at Time 2 significantly correlated with personal beliefs, both selfcontrol variables did not correlate with them.
The change in PWB at Time 2 in relation to self-control was assessed by a multiple regression analysis which included PWB at Time 1 entered on stage 1, two selfcontrol variables entered on stage 2 , engagement in oral sex since Time 1 entered on stage 3 , and the perceived changes in PWB and sex life on stage 4 and students' religious or personal beliefs on stage 5 .

The results are summarised in Table 3 .

\begin{tabular}{|c|c|c|c|c|c|c|c|c|c|}
\hline \multirow{2}{*}{ Predictors } & \multicolumn{3}{|c|}{ All } & \multicolumn{3}{|c|}{ Male } & \multicolumn{3}{|c|}{ Female } \\
\hline & $\boldsymbol{\beta}$ & $\mathbf{R}^{2}$-change & Final $\beta$ & $\boldsymbol{\beta}$ & $\mathbf{R}^{2}$-change & Final $\beta$ & $\beta$ & $\mathbf{R}^{2}$-change & Final $\beta$ \\
\hline $\begin{array}{c}\text { Step1 } \\
\text { T1PWB }\end{array}$ & $.57^{* * *}$ & .26 & $.44^{* * *}$ & $.73^{* * *}$ & .53 & $.75^{* * *}$ & $.58^{* * *}$ & .34 & $.41^{* * *}$ \\
\hline Step2 Trait Self Control & $.39 * * *$ & .16 & $.17^{* *}$ & & & & $.18^{*}$ & .03 & $.30^{* * *}$ \\
\hline $\begin{array}{c}\text { Step3 } \\
\text { Received Oral } \\
\text { Given Oral } \\
\end{array}$ & & & & $\begin{array}{l}.23^{* *} \\
-.41^{*}\end{array}$ & $\begin{array}{l}.05 \\
.04\end{array}$ & $\begin{array}{l}.66^{* * *} \\
-.39^{* *}\end{array}$ & & & \\
\hline $\begin{array}{c}\text { Step4 } \\
\text { PercChange PWB } \\
\text { Perc Change sex } \\
\end{array}$ & $\begin{array}{c}.21^{* * *} \\
-.15^{*}\end{array}$ & $\begin{array}{l}.04 \\
.02\end{array}$ & $\begin{array}{l}.29^{* * *} \\
-.19^{* * *} \\
\end{array}$ & $\begin{array}{l}.28^{* *} \\
-23^{* *}\end{array}$ & $\begin{array}{l}.06 \\
.04\end{array}$ & $\begin{array}{c}.28^{* *} \\
-.34^{* * *}\end{array}$ & $.21^{* *}$ & .04 & $.21^{* *}$ \\
\hline $\begin{array}{c}\text { Step5 } \\
\text { Personal Beliefs }\end{array}$ & $.26^{* * *}$ & .06 & $.26^{* * *}$ & & & & $32^{* * *}$ & .09 & $.32^{* * *}$ \\
\hline Notes: & \multicolumn{3}{|c|}{$\mathrm{N}=180, \mathrm{R}^{2}=.5$} & \multicolumn{3}{|c|}{$\mathrm{N}=57, \mathrm{R}^{2}=.72$} & \multicolumn{3}{|c|}{$\mathrm{N}=123, \mathrm{R}^{2}=.50$} \\
\hline
\end{tabular}

Note: ${ }^{*} \mathrm{p}<.05 ;{ }^{* *} \mathrm{p}<.01$ and ${ }^{* * *} \mathrm{p}<.001$

Table 3: Multiple regression analysis predicting PWB at Time2.

The analysis revealed that, in total, students' PWB at Time 2 was predicted by their PWB at Time 1 (accounting for $26 \%$ of variances), their trait self-control (16\%), their perception of changes in PWB (4\%) and in sexual life $(2 \%)$ and their personal beliefs $(6 \%)$.

The picture appeared to differ for genders.
For male students, TSC was not a significant predictor of PWB at Time 2. For males, $53 \%$ of variances in their PWB at Time 2 were accounted to their PWB at Time 1, $10 \%$ to their perception of changes in their PWB and sexual life, and $9 \%$ to their engagement in oral sex (receiving oral sex predicted a significant improvement 


\section{Psychology \& Psychological Research International Journal}

whereas giving oral sex predicted a significant decline in their PWB at Time2).

For female students, trait self-control appeared to be a significant predictor of their PWB at Time 2 (3\%). While $34 \%$ of variances in their PWB at Time 2 were explained by their PWB at Time 1, 4\% related to their perception of changes in their PWB and 9\% were due to their personal beliefs.

\section{Discussion}

\section{The Difference between Trait Self-Control and Sexual Self-Control in their Impact on Students' Oral Sex Behaviour}

Overall, we found no gender differences in engagement in oral sex behaviour. As we expected, students' engagement in oral sex was significantly associated with both types of self-control. Respondents with low selfcontrol scores consistently demonstrated higher levels of engagement in oral sex behaviour.

Nevertheless, the relationship between engagement in oral sex and trait self-control and sexual self-control differed on two time assessment points.

At the cross-sectional level, engagement in both giving and receiving oral sex was directly linked to sex-related self-control, while only engagement in giving oral sex was directly linked to trait self-control. In line with previous research grounded in self-control resource model [9]; the negative impact of low trait self-control and less ability to restrain sexual behaviour was evident in a higher engagement in oral sex. When the relationship was tested over a longer time period, the impact of trait self-control on engagement in oral sex behaviour was no longer evident. However, the differences in ability to restrain sexual behaviour (i.e. sexual self-control) continued to significantly affect engagement in oral sex in longitudinal part of the study. In addition, trait self-control and sexual self-control on Time 2 remained positively and moderate correlated with each other.

The strength of these correlations may indicate that, although both types of self-control belong to the same self-regulation domain, they appeared to be different in the ways how they affect individual's sexual behaviour.

There are could be a few possible explanations for our findings.
First, we may suggest that the relationship between trait and sexual self-control could be mediated by a third element in regulating oral sex behaviour, such as motivation or attention [36,37]. This implies that the influence of this third element would be more evident in behaviour that holds a particular importance for each individual.

Second, we may propose that sexual self-control can act as an immediate response to the certain everyday behavioural temptation from the individual's environment (e.g. sexual temptation), and thus to be applied 'here and now', in a very first instance, or in ego depletion, when the resources of self-control are exhausted by environmental/situational demands or diverted on performing the other perhaps more important tasks [38].

\section{The Difference between Trait Self-Control and Sexual Self-Control in Their Impact on Students' PWB}

The link between self-control and students' PWB provided additional flavour to the relationship between two types of self-control.

Overall, males demonstrated significantly better PWB than female on Time 1 assessment point but in follow up study the difference in PWB between male and females was no longer significant. Both, males and females, reported improved PWB in longitudinal study. This improvement can be attributed to their adjustment to the university campus life. According to our results, females managed to adjust to the university life better than males.

In total, we found the significant association between PWB and trait self-control. Students with high level of self-control demonstrated higher levels of PWB on baseline and over 4 month's period of time. Accounting for gender, the importance of trait self-control and sexual self-control varied in predicting PWB on two assessment points.

On the cross sectional level, both type of self-control (TSC and SSC) were significant predictors of PWB for males but not for females. For females, only trait selfcontrol (but not sexual self-control) and the number of oral sex partners were associated with better PWB on their entering to the university life.

On the longitudinal level, for both males and females, the baseline PWB score at Time1 was found to be the best 


\section{Psychology \& Psychological Research International Journal}

indicator of PWB at time 2. The influence of trait selfcontrol on PWB was found to be more salient for females than for males. Notably, females demonstrated better psychological adjustment to the university life than males. For males, neither trait self-control nor sexual self-control significantly contributed to their PWB over four month's time. A significant improvement in PWB for males was mainly predicted by their PWB at the baseline and was rather dependent on them receiving oral sex than on their level of both types of self-control, whereas a significant decline in their PWB was due to giving oral sex over this period of time.
As for females, the association between high trait selfcontrol and better psychological adjustment is consistent with the findings from the previous research on benefits of self-regulation. The picture looks more complicated for males. Looking for further explanations for these findings, we turned to part 2 of our study.

\section{Part 2 Results}

\section{Descriptives}

The correlations between self-control variables and RFO variables are represented in Table 4.

\begin{tabular}{|c|c|c|c|c|c|}
\hline Variable & M & SD & $\mathbf{2}$ & $\mathbf{3}$ & $\mathbf{4}$ \\
\hline 1.TraitSelfControl & 41.84 & 8.33 & $.44^{* *}$ & $.43^{* *}$ & $.43^{* *}$ \\
\hline 2.PromoteRFO & 20.87 & 3.19 & & .12 & .09 \\
\hline 3.PreventRFO & 17.05 & 3.97 & & & $.41^{* *}$ \\
\hline 4.Total Sexual SelfControl & 36.71 & 8.35 & & & \\
\hline
\end{tabular}

Note: $\mathrm{N}=180,{ }^{*} \mathrm{p}<.05 ;{ }^{* *} \mathrm{p}<.01$ and ${ }^{* * *} \mathrm{p}<.001$.

Table 4: Means, SDs and correlations of self-control and RFQ variables.

As it could be seen from the table, TSC correlated significantly with both RFQ variables; whereas SSC correlated with preventive but not with promote RFO. As expected, two RFO variables did not correlate with each other.

\section{Impact of RFO on PWB at Time 2}

Impact of RFO on PWB at Time 2 was assessed by a multiple regression equations predicting PWB at Time 2 . This regression analysis assessed students' PWB at Time 2 by regressing sequential steps: PWB at Time 1 on stage 1 , two self-control variables on stage 2 , engagement in oral sex since Time 1 on stage 3, perceived changes in PWB/ Sexual life on stage 4, two RF0 variables on stage 5 and students' personal beliefs on stage 6 . The results are summarised in Table 5.
The results revealed that addition of promote RFO to the equation undermined the effect of trait self-control on predicting PWB at Time 2 and, in total, increased the amount of variance accounting for PWB at Time 2 by students baseline PWB at Time 1 (from 26 to 40\%).

Whereas students' perception of changes in their PWB and sexual life hold $6 \%$ of predictive power, the influence of promote RFO accounted for $12 \%$ in PWB at Time 2.

This picture differed by gender. Whereas for male students RFOs did not bring any difference to PWB, for female students promote RFO replaced the effect of trait self-control in predicting their PWB at Time 2, accounting for $17 \%$ of variance explained.

\begin{tabular}{|c|c|c|c|c|c|c|c|c|c|}
\hline \multirow{2}{*}{ Predictors } & \multicolumn{3}{|c|}{ All } & \multicolumn{3}{|c|}{ Male } & \multicolumn{3}{|c|}{ Female } \\
\hline & $\boldsymbol{\beta}$ & $\mathbf{R}^{2}$-change & Final $\beta$ & $\boldsymbol{\beta}$ & $R^{2}$-change & Final $\beta$ & $\boldsymbol{\beta}$ & $R^{2}$-change & Final $\beta$ \\
\hline $\begin{array}{c}\text { Step 1 } \\
\text { T1PWB }\end{array}$ & $.63^{* * *}$ & .40 & $.35^{* * *}$ & $.73^{* * *}$ & .53 & $.75^{* * *}$ & $.58^{* * *}$ & .34 & $.32^{* * *}$ \\
\hline \begin{tabular}{|c|} 
Step 2 \\
Trait Self Control
\end{tabular} & $.153^{*}$ & .02 & .11 & & & & $.18^{*}$ & .03 & .10 \\
\hline $\begin{array}{c}\text { Step3 } \\
\text { Received Oral } \\
\text { Given Oral }\end{array}$ & & & & $\begin{array}{l}.23^{* *} \\
-.41^{*}\end{array}$ & $\begin{array}{l}.05 \\
.04\end{array}$ & $\begin{array}{l}.66^{* * *} \\
-.39^{* *}\end{array}$ & & & \\
\hline $\begin{array}{c}\text { Step } 4 \\
\text { Perc Change } \\
\text { PWB }\end{array}$ & $\begin{array}{l}.21^{* * *} \\
-.15^{*}\end{array}$ & $\begin{array}{l}.04 \\
.02\end{array}$ & $\begin{array}{l}.29^{* * *} \\
-.16^{* *}\end{array}$ & $\begin{array}{l}.28^{* *} \\
-23^{* *}\end{array}$ & $\begin{array}{l}.06 \\
.04\end{array}$ & $\begin{array}{l}.28^{* *} \\
-.34^{* * *}\end{array}$ & $.21^{* *}$ & .04 & $.08^{* *}$ \\
\hline
\end{tabular}




\section{Psychology \& Psychological Research International Journal}

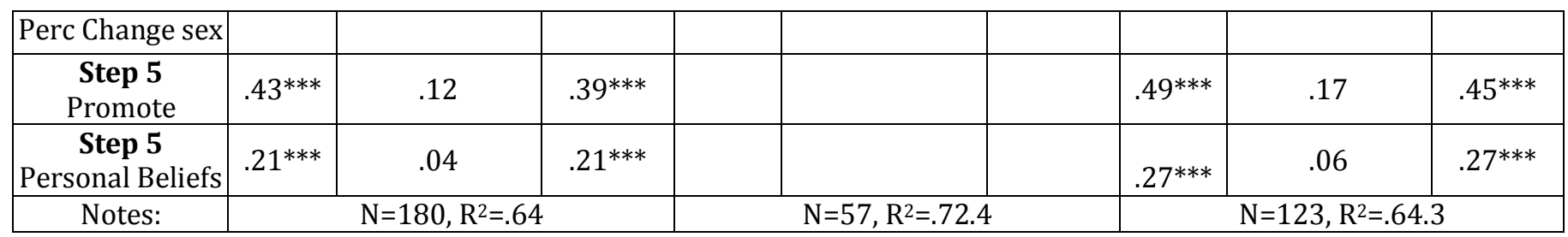

Note: ${ }^{*} \mathrm{p}<.05 ;{ }^{* *} \mathrm{p}<.01$ and ${ }^{* * *} \mathrm{p}<.001$

Table 5: Multiple regression analysis predicting PWB at Time2, including RFO

Relationship between Rfos and Self-Control Variables, and their Influence on PWB At Time 2

To investigate the relationship between RFOs and all other variables presented in previous analysis, we repeated the same regression in the same sequential steps on each of RFOs taken as dependent variables, in total and for genders. The results are presented in Table 6 and 7.

\begin{tabular}{|c|c|c|c|c|c|c|}
\hline Predictors & \multicolumn{3}{|c|}{ Promote RFOa } & \multicolumn{3}{c|}{ Preventive RFOb } \\
\cline { 2 - 7 } & $\boldsymbol{\beta}$ & $\mathbf{R}^{2}$-change & Final $\boldsymbol{\beta}$ & $\boldsymbol{\beta}$ & $\mathbf{R}^{2}$-change & Final $\boldsymbol{\beta}$ \\
\hline $\begin{array}{c}\text { Step 1 } \\
\text { t2PWB }\end{array}$ & $.66^{* * *}$ & .42 & $.54^{* * *}$ & & & \\
\hline $\begin{array}{c}\text { Step 2 } \\
\text { Sexual Self Control }\end{array}$ & & & & $.36^{* * *}$ & .13 & .10 \\
\hline $\begin{array}{c}\text { Step 3 } \\
\text { Trait Self Control }\end{array}$ & $.21^{* * *}$ & .04 & $22^{* * *}$ & $.35^{* * *}$ & .09 & $.33^{* * *}$ \\
\hline $\begin{array}{c}\text { Step 4 } \\
\text { t2 Oral sex part }\end{array}$ & & & & $-.23^{* * *}$ & .05 & $-.25^{* * *}$ \\
\hline $\begin{array}{c}\text { Step 5 } \\
\text { t2 Perceived Change PWB }\end{array}$ & $.11^{*}$ & .01 & $.11^{*}$ & & & \\
\hline $\begin{array}{c}\text { Step 6 } \\
\text { Religious beliefs }\end{array}$ & & & & $.16^{*}$ & .03 & $.16^{*}$ \\
\hline
\end{tabular}

Note 1: a $\mathrm{R}^{2}=.49 ;{ }^{\mathrm{b}} \mathrm{R}^{2}=.29 ; \mathrm{N}=180$

Note 2 : $^{*}<<.05 ;{ }^{* *} \mathrm{p}<.01$ and ${ }^{* * *} \mathrm{p}<.001$.

Table 6: Multiple regression analysis explaining interactions between RFO and other important variables.

\begin{tabular}{|c|c|c|c|c|c|c|c|c|c|c|c|c|}
\hline \multirow{4}{*}{$\begin{array}{c}\text { Predictors } \\
\text { Step 1 } \\
\text { T2PWB } \\
\end{array}$} & \multicolumn{6}{|c|}{ Promote RFQ } & \multicolumn{6}{|c|}{ Prevent RFQ } \\
\hline & \multicolumn{3}{|c|}{ Male } & \multicolumn{3}{|c|}{ Female } & \multicolumn{3}{|c|}{ Male } & \multicolumn{3}{|c|}{ Female } \\
\hline & \multirow{2}{*}{\begin{tabular}{|c|}
$\boldsymbol{\beta}$ \\
$66^{* * * *}$ \\
\end{tabular}} & \multicolumn{2}{|c|}{$\mathbf{R}^{2}$-change Final $\beta$} & $\beta$ & \multicolumn{2}{|c|}{$\mathbf{R}^{2}$-change Final $\beta$} & \multirow[t]{2}{*}{$\beta$} & \multicolumn{2}{|c|}{$\mathbf{R}^{2}$-changeFinal $\beta$} & \multirow[t]{2}{*}{$\beta$} & $\mid \mathrm{R}^{2}$-change Final & Final $\beta$ \\
\hline & & .43 & $.66^{* * *}$ & $66^{* * *}$ & .44 & $.55^{* * *}$ & & & & & & \\
\hline $\begin{array}{c}\text { Step } 2 \\
\text { Sexual Self Control }\end{array}$ & & & & & & & $.35^{* *}$ & .12 & $.25^{*}$ & $38^{* * *}$ & .14 & $.19^{*}$ \\
\hline $\begin{array}{c}\text { Step } 3 \\
\text { Trait Self Control }\end{array}$ & & & & $.18^{* *}$ & .03 & $.19^{* *}$ & & & & $.41^{* *}$ & .13 & $.41^{* *}$ \\
\hline $\begin{array}{c}\text { Step } 4 \\
\text { T2Receivedoralsex }\end{array}$ & & & & & & & $-.36^{* *}$ & .13 & -.16 & & & \\
\hline $\begin{array}{c}\text { Step 5 } \\
\text { t2Vagsexpart } \\
\text { t2Oralsexpart }\end{array}$ & $-.27 * *$ & .06 & $-.31^{* *}$ & & & & $-.44^{*}$ & .08 & $-.39 *$ & & & \\
\hline $\begin{array}{c}\text { Step } 6 \\
\text { PercevChangePWBt2 }\end{array}$ & & & & $.18^{*}$ & .03 & $.18^{*}$ & & & & & & \\
\hline
\end{tabular}




\section{Psychology \& Psychological Research International Journal}

\begin{tabular}{|c|c|c|c|c|c|c|c|c|}
\hline $\begin{array}{c}\text { Step } 7 \\
\text { Personal beliefs } \\
\text { Religious beliefs }\end{array}$ & $.22^{*}$ & .04 & $.22^{*}$ & & $.32^{* *}$ & .09 & $.32^{* *}$ & \\
\hline & \multicolumn{3}{|c|}{$\mathrm{N}=57, \mathrm{R}^{2}=.54$} & $\mathrm{~N}=123, \mathrm{R}^{2}=.49$ & \multicolumn{3}{|c|}{$\mathrm{N}=57, \mathrm{R}^{2}=.42$} & $\mathrm{~N}=123, \mathrm{R}^{2}=.27$ \\
\hline
\end{tabular}

Note: ${ }^{*} \mathrm{p}<.05 ;{ }^{* *} \mathrm{p}<.01$ and ${ }^{* * *} \mathrm{p}<.001$.

Table 7: Multiple regression analysis explaining interactions between RFO and other important variables.

In total, TSC appeared to be important for both types of RFOs, but controlling for gender, it was significantly important for females but not for males. SSC was significantly associated with preventive RFO (in total and for both genders), and was inversely associated with the number of oral sex partners since Time1. For male students, preventive RFO was also inversely associated with receiving oral sex since Time 1 .

In comparison with preventive RFO, promote RFO was significantly and positively associated with PWB at Time2 (in total and for both genders). Promote RFO also had a significant association with perceptions of changes in PWB for female students but not for male students. For males, promote orientation was inversely associated with the number of vaginal sex partners. While promote RFO was positively associated with personal beliefs, preventive RFO was positively associated with religious beliefs in males but not in females.

\section{Promote Focus Orientation and PWB at Time 2 in Relation to Engagement in Oral Sex}

Finally, we investigated how students' RFOs can affect their PWB at Time2, in relation to their engagement in oral sex.

Amongst all participants who reported engagement in oral sex since Time 1, there were approximately $60 \%$ of participants with relatively more Promote orientation and around $40 \%$ participants with relatively more Prevention orientation. The results of logistic regression indicated that, in total, higher Promote scores (controlled for Prevention scores) were positively related to having good PWB, $\beta=1.69, p=.001$, whereas higher Prevention scores (controlling for Promotion scores) were not, $\beta=.46$, $p>.06$.

Among the promote orientated participants, more than $85 \%$ of students, who had not receive oral sex since Time 1 , and around $82 \%$ of students, who received oral sex since Time 1, reported good PWB at Time 2. Among the prevention orientated participants, $55 \%$ of students, who did not receive oral sex since Time 1 , and $52 \%$ of students, who received oral sex since Time 1, reported good PWB at Time 2 . These differences were statistically significant in both cases: $t(1,180)=7.43 ; \mathrm{p}=.01$ and $\mathrm{t}(1$, 180) $=11.28 ; p=.001$, respectively.

Accordingly, among the promote orientated participants, about $86 \%$ of students, who had not given oral sex since Time 1 , and around $82 \%$ of students, who had not given oral sex since Time 1, reported good PWB at Time 2. Among the prevention orientated participants, around $58 \%$ of students, who had not given oral sex since Time 1, and $51 \%$ of students, who given oral sex since Time 1, reported good PWB at Time 2. These differences were also statistically significant in both cases: $t(1,180)$ $=6.73 ; \mathrm{p}=.01$ and $\mathrm{t}(1,180)=11.79 ; \mathrm{p}=.001$, respectively.

Whereas, as related to oral sex engagement and regulatory focus orientation, there was no significant difference in PWB for males, this difference existed for females (Table 8).

\begin{tabular}{|c|c|c|c|c|c|c|c|c|}
\hline \multirow{3}{*}{ PWB } & \multicolumn{4}{|c|}{ Given oral sex } & \multicolumn{4}{|c|}{ Received oral sex } \\
\hline & \multicolumn{2}{|c|}{$\begin{array}{c}\text { No } \\
(\mathrm{N}=44)\end{array}$} & \multicolumn{2}{|c|}{$\begin{array}{c}\text { Yes } \\
(\mathrm{N}=79)\end{array}$} & \multicolumn{2}{|c|}{$\begin{array}{c}\text { No } \\
(\mathrm{N}=48)\end{array}$} & \multicolumn{2}{|c|}{$\begin{array}{c}\text { Yes } \\
(\mathrm{N}=75)\end{array}$} \\
\hline & $\begin{array}{c}\text { Prevent } \\
(\mathrm{N}=14)\end{array}$ & $\begin{array}{c}\text { Promote } \\
(\mathrm{N}=30)\end{array}$ & $\begin{array}{c}\text { Prevent } \\
(\mathrm{N}=34)\end{array}$ & $\begin{array}{c}\text { Promote } \\
(\mathrm{N}=45)\end{array}$ & $\begin{array}{c}\text { Prevent } \\
(\mathrm{N}=15)\end{array}$ & $\begin{array}{c}\text { Promote } \\
(\mathrm{N}=33)\end{array}$ & $\begin{array}{c}\text { Prevent } \\
(\mathrm{N}=33)\end{array}$ & $\begin{array}{c}\text { Promote } \\
(\mathrm{N}=42)\end{array}$ \\
\hline Poor & $7(50)$ & $5(11.6)$ & $19(55.9)$ & $10(22.2)$ & $8(53.3)$ & $6(18.2)$ & $18(54.5)$ & $9(21.4)$ \\
\hline Good & $7(50)$ & $25(83.3)$ & $15(44.1)$ & $35(77.8)$ & $7(46.5)$ & $27(81.8)$ & $15(45.6)$ & $33(78.6)$ \\
\hline Notes: & \multicolumn{2}{|c|}{$\begin{array}{c}\chi^{2}(1,1)=5.35 \\
p=.03\end{array}$} & \multicolumn{2}{|c|}{$\begin{array}{c}\chi^{2}(1,1)=9.45 \\
p=.004\end{array}$} & \multicolumn{2}{|c|}{$\begin{array}{c}\chi^{2}(1,1)=6.17 \\
p=.02\end{array}$} & \multicolumn{2}{|c|}{$\chi^{2}(1,1)=8.79 ; p=.004$} \\
\hline
\end{tabular}

Table 8: Females' PWB as related to their RFQ group and their engagement in oral sex. 


\section{Psychology \& Psychological Research International Journal}

\section{Discussion}

One of the main findings of the Part 2 was that regulatory focus orientation hold greater predictive power on PWB at Time 2 than trait self-control. The fact that RFO literally has taken the place of trait self-control in predicting PWB at Time 2 demonstrated that, for females, the role of trait self-control in psychological adjustment, as related to sexual behaviour, can be as significant as the role of regulatory focus orientation. The impact of promote orientation and trait self-control was associated with better PWB at Time 2 for females.

For males, neither trait self-control nor promote orientation were significant for improvement in their PWB at Time 2. For them, engagement in oral sex and perceived changes in $\mathrm{PWB} /$ sexual life appeared to be more important components contributing to their PWB than any self-regulation variables (i.e. trait self-control and RFO).

As for RFOs, the finding that promote and preventive orientations weren't correlated with each other at all was consistent with a previous research and demonstrate the conceptual difference between these two RFOs [35].

This difference provides us with additional hint into divergence between trait and sexual self-control. In total, promote RFO was clearly associated with trait selfcontrol, while preventive RFO was associated with both trait and sexual self-control. There were no any association between promote RFO and sexual self-control as related to PWB and oral sex behaviour. Can we accept this as the evidence that sexual self-control is mainly involved in securing the desired outcome of sexual behaviour but not PWB associated with this behaviour?

Furthermore, our findings indicated that, for females, trait self-control appeared to be a driven force for both regulatory focus orientations. The situation with sexual self-control was more complicated. Sexual self-control was associated with preventive regulatory focus orientation in both, males and females. For females with preventive regulatory orientation, both type of selfcontrol were nearly equally important for their regulatory orientation. For males, preventive orientation was associated with sexual self-control but not with trait sexcontrol, whereas promote regulatory focus orientation had no association with any types of self-control. Does it imply that the males striving for accomplishment in sexual behaviour may suffer from the lack of trait self- control? Promote orientated males appeared to benefit from strong personal beliefs and reported to have less vaginal sex partners since time 1, while preventive orientated males rather took advantage of the strength of their religious beliefs and reported to have less oral sex partners since time 1 .

Finally, although female students' PWB at Time 2 was associated with their trait self-control and promote regulatory focus orientation, it was also related with their perception of positive changes in their PWB since time 1 and with the strength of their personal beliefs.

At the same time, although male students' PWB at Time 2 related to their perception of positive change in their PWB and receiving oral sex since time 1, it was also associated with their perception of negative change in their sexual life and giving oral sex over this period of time.

\section{General Discussion}

The primary purpose of this study was to explore the relationships between trait self-control and sexual selfcontrol on the example of oral sex behaviour and psychological well-being. The role of trait self-control and sexual self-control was investigated on both crosssectional and longitudinal levels, thereby allowing us to assess the longevity of outcomes.

The findings from this study pointed towards at least operational difference between trait self-control and sexual self-control on both cross-sectional and longitudinal levels.

At the cross-sectional level students with higher sexual self-control demonstrated lower engagement in both giving and receiving oral sex, whereas students with higher trait self-control demonstrated lower engagement only in giving oral sex. When these associations were tested over period of time, the impact of trait self-control on engagement in oral sex was no longer evident. However, the differences in ability to restrain sexual behaviour continued to significantly impact oral sex behaviour.

In this study we found that the influence of trait selfcontrol on PWB and was significantly stronger than the influence of trait self-control on oral sex behaviour. Students with high level of trait self-control demonstrated 


\section{Psychology \& Psychological Research International Journal}

higher levels of PWB on baseline and over 4 month's period of time.

There was also a clear gender difference in the way how trait self-control affected students' PWB.

At the cross sectional level, both types of self-control were significant contributors to better PWB for males but not for females. At the longitudinal level, better PWB was associated with students' baseline PWB and their oral sex behaviour (giving and receiving oral sex) but not with trait self-control or sexual self-control. For females, only trait self-control (but not sexual self-control) was consistently associated with good PWB at time 1 and time 2. It worth to notice, that females demonstrated better psychological adjustment to the university life than males.

Furthermore, we found male students to score significantly higher on sexual self-control than females but we did not found any differences between genders in trait self-control. Generally, males are argued to have stronger sexual desires then females; therefore, it is possible for males to exhibit higher level of sexual selfcontrol then females simply because in their everyday life they have to exercise it more often then females? Results from the previous studies indicated that in ego depletion, males with low trait self-control were more susceptible to self-control failures in sexual behaviour than females with low trait self-control [7]. In light of suggested difference between trait and sexual self-controls in sexual behaviour, it sounds plausible that ego depletion may in first instance affect domain-related, i.e. sexual self-control, than more general purpose trait self-control? This is a perspective avenue for a future research.

Considering self-control in combination with RFO, we found association between trait self-control and promote regulatory focus orientation in predicting PWB in females on longitudinal level. In males, neither type of self-control nor RFOs was associated with better PWB on longtutudinal level. Trait self-control appeared to be a significant component of promote RFO in females, while sexual self-control was a significant component of preventive RFO in males. Interestingly, both types of selfcontrol were significantly important constituents of preventive RFO in females. Taken outside RFO framework, these findings can mean that, in relation to risky sexual behaviour, females with promote orientation could benefit from exercising their sexual self-control.
Overall, females with promote orientation reported significantly higher PWB at time point 2 than females with preventive orientation, irrespective of whether they were engaged in oral sex or not.

The nature of this influence is argued to lie in the ways how cognitive re-appraisal processes work for each of this RFOs. As we did not manipulate it situationally (e.g. using priming), the possible explanation could be based on Higgins' concept of a 'natural fit', suggesting that individuals can assign different importance to the same outcomes as a function of the relevance of these outcome to their regulatory orientation. From this point of view, it is possible that promotion orientated females take their experience of engagement/non engagement in oral sex more positively than prevention orientated participants and, consequently, demonstrated better adjustment to their oral sex behaviour and better PWB, irrespectively of quality of their personal oral sex experiences. This also suggests that for females with promote orientation, it will be easy to change their negative attitudes to and perception of oral sex as a result of their changing goals and priorities, therefore, having or developing promote orientation will be beneficial for behavioural interventions aimed to improve mental health.

Further research may explore the effect of the RFOs and self-control in different situations. Better results may be achieved through studying a wider age group, by following young adults over a longer period of time, or through studying a purposive sample of those young adults with different levels of trait and sexual selfcontrols.

Altogether, our findings give the further thoughts about the nature of difference between two types of self-control. In formulating the essence of this possible difference, we shall refer to the work of Hofmann \& Kotabe (2012) [39]. Their concept of preventive and interventive types of selfcontrol suggests that self-control is not unitary phenomenon but rather a collection of different types/cases that may serve their purpose within a broad stream of self-regulation processes.

Our findings, therefore, support the suggestion that trait self-control in sexual behaviour may serve as a generally preventive type of self-control (i.e. as anticipatory strategies), whereas sexual self-control may serve as intervention type of self-control (i.e. as the use of the willpower in the 'heat of the moment'). 


\section{Psychology \& Psychological Research International Journal}

In favour of this suggestion, there are the findings from several domains of health-related behaviour that the most successful self-regulators often not entirely rely on their high self-control abilities but rather use different strategies to avoid any tempting situations [40]. The most popular of these strategies is simply withdrawing the tempting stimuli, social and situational cues leading to temptation from the individual's environment.

The suggestion that preventive behavioural strategies are supported by higher trait self-control abilities is in accordance with the results of studies on trait self-control in ego depletion [26]. These studies found that high in trait self-control (but low in domain-specific self-control) individuals, taken from the 'safety net' of their preventive behaviour, demonstrated lower ability to resist acute temptations than individuals with lower level of trait selfcontrol (i.e. 'ironic effects of high trait self-control'). The latter are the individuals who are frequently fighting temptations in their daily routines using and exercising their dispositional, domain-specific, self-control, which supports their interventive behavioural strategies. By using them routinely they develop higher ability to resist temptation and higher domain-specific self-control. This allows them to successfully use them in everyday life to fight acute temptations. This explanation is also within the existing resource model of self-control [1].

Naturally, this suggestion does not imply strict categorisation of functions between different types of selfcontrol, and trait self-control is always in one or other way is present in everyday behaviour. Our findings and suggestions are rather applying to 'here and now' sexual behavioural responses in daily routine life. The notion of operational difference between two types of self-control therefore offers a new prospective line of research.

\section{Limitations}

The current study had several limitations.

The first limitation was in the use of self-report measures; a method that can result in participants responding in a socially desirable way. To limit social desirability in responding, our survey was anonymous, Internet-based and self-administered. However, while self-administered questionnaires were found to provide a more private, less intrusive, and less threatening means of reporting sensitive behaviours, on the other side, selfadministration could result in precluding additional clarification of unclear questions, thus increasing the chance for missing responses or inconsistent data reporting [41-44]. To minimise these errors and to improve overall measurement precision, most of the measures we used were already established, psychometrically validated questionnaires. Therefore, although subject to a certain degree of error, the selfreport measures used to collect sexual behaviour data in this research were considered to be a justifiable and appropriate choice.

The next methodological limitation of the current study was that although our final sample included 180 students, only a relatively small number $(20-27 \%$ of students) transitioned to oral sex in the first semester of the university, consequently, the psychological well-being analysis was underpowered. In addition, the sample size and the sample characteristics (e.g. $70 \%$ of females) prevented us from fully exploring the gender effect of trait and sexual self-controls on oral sex behaviour and PWB on both time points. Besides, a male sample in this survey was too small to make valuable inferences about the reported effects of self-control on PWB for males. Further research need to explore these effects on the larger male samples and include a wider range of first year university male students.

Next to methodological limitations, our study was also limited in its longitudinal part. The following reassessment period, although providing valuable and meaningful results, ideally needs to cover a longer period of time and possibly include a third point of assessment at the end of an academic year. Longer-term follow-up intervals will allow more time for delayed effects to emerge and, therefore, provide better information on the durability of these effects and patterns of changes. Extending the study to measure outcomes on three or more occasions will also increase the confidence that the findings reflect real effects rather than transient fluctuations.

Better results may be also achieved through studying a purposive sample of only those respondents who do report high/low combination of trait and sex-related selfcontrol or significant improvement/ deterioration of their PWB.

Finally, a fruitful path for future research will be in exploring the mechanisms of engagement in oral sex behaviour in different types of ego depletion (e.g. physical tiredness, cognitive load, alcohol intoxication and emotional rise). Each of these ego depletion states need to be investigated separately in order to understand the 


\section{Psychology \& Psychological Research International Journal}

interplay between two types of self-control and, perhaps, motivation to control sexual behaviour in shaping engagement in oral sex, controlling for gender, and accounting for other important variables such as relationship power pressure.

\section{Conclusions and Implications}

The current study aimed to contribute to existing body of knowledge on behavioural self-regulation by exploring the relationship between trait and domain specific selfcontrol in area of sexual behaviour and PWB.

Our results indicated that both trait and sexual selfcontrol appeared to play important role in regulating oral sex behaviour but their functions somehow differ in this regulation. While both types of self-control were important for engagement in oral sex in general, only sexual self-control found to have a longevity effect for this behaviour over time. The proposed functional difference between two types of self-control was also evident in assessing PWB.

Investigating relationship between trait and sexual self-controls and their effects on both sexual and nonsexual behaviour challenged the view on self-control as 'intact entity' in regulating any type of behaviour and provided the evidence that the regulation of domainspecific behaviour may be more heavily based on domainspecific type of self-control., in our case sexual self-control in oral sex behaviour.

In conclusion, we would like to stress that the present research is linked with and built on previous research work on self-control and self-regulation. We measured and reported standardised constructs of trait self-control and sexual restraint. Our results produced some findings and raised some questions that we presently cannot explain and cannot answer. These findings, if confirmed, will need further research and explanations.

Findings from this study highlighted the importance of developing stronger sexual self-control in managing sexual behaviour in everyday life and can be used to further inform intervention programmes aimed to facilitate sexual behaviour change. They suggest that a useful approach to promote safe sexual behaviour may be in training young people, especially young females, to manage their sexual behaviour in everyday situations. This includes the role play games that are already incorporated in some sex education programmes in schools. The experience of fighting temptations could provide young people and adolescents with the opportunity to exercise and strengthen their sexual selfcontrol that will be highly beneficial for them 'here and now' and later on, when they move out of the 'safety and comfort zone' of their family and friends.

\section{Acknowledgements}

Funding: None

Competing interests: None declared

Ethical approval: University of Bath Psychology Ethics Committee (Ref: 12-121)

\section{References}

1. Baumeister RF, Vohs KD, Tice DM (2007) The strength model of self-control. Current Directions in Psychological Science 16(6): 351-355.

2. Baumeister RF, Heatherton TF, Tice DM (1994) Losing Control: How and Why People Fail at SelfRegulation. San Diego, CA: Academic Press.

3. Baumeister RF, Bratslavsky M, Muraven M, Tice DM (1998) Ego depletion: Is the active self a limited resource? J Pers Soc Psychol 74(5): 1252-1265.

4. Carver CS, Scheier MF (1982) Control theory: A useful conceptual framework for personality: How interventions increase regulatory success, and how depletion moderates the personality-social, clinical and health psychology. Psychol Bull 92(1): 111-135.

5. Carver CS, Scheier MF (1998) On the Self-Regulation of Behaviour. New York, NY: Cambridge University Press.

6. Higgins ET (1987) Self-discrepancy: A theory relating self and affect. Psychol Rev 94(3): 319-340.

7. Tangney JP, Baumeister RF, Boone AL (2004) High self-control predicts good adjustment, less pathology, better grades, and interpersonal success. J Pers 72(2): 271-322.

8. Duckworth AL, Seligman MEP (2005) Self-discipline outdoes IQ in predicting academic performance of adolescents. Psychol Sci 16(12): 939-944.

9. Gailliot MT, Baumeister RF (2007) Self-regulation and sexual restraint: Dispositionally and temporarily poor 


\section{Psychology \& Psychological Research International Journal}

self-regulatory abilities contribute to failure at restraining sexual behaviour. Pers Soc Psychol Bull 33(2): 173-186.

10. Bogg T, Roberts BW (2004) Conscientiousness and Health-Related Behaviours: A Meta-Analysis of the Leading Behavioural Contributors to Mortality. Psychol Bull 130(6): 887-919.

11. Verdejo-Garcia A, Lawrence AJ, Clark L (2008) Impulsivity as a vulnerability marker for substanceuse disorders: Review of findings from high-risk research, problem gamblers and genetic association studies. Neurosci Biobehav Rev 32(4): 777-810.

12. Verplanken B, Sato A (2011) The Psychology of Impulse Buying: An Integrative Self-Regulation Approach. Journal of Consumer Policy 34 (2): 197210.

13. Van Koningsbruggen GM, Stroebe W, Papies EK, Aarts H (2011) Implementation intentions as goal primes: Boosting self control in tempting environments. European Journal of Social Psychology 41: 551-557.

14. Keller C, Siegrist M (2014) Successful and unsuccessful restrained eating. Does dispositional self-control matter? Appetite 74: 101-106.

15. Shoda Y, Mischel W, Peake PK (1990) Predicting adolescent cognitive and self-regulatory competencies from preschool delay in gratification: Identifying diagnostic conditions. Developmental Psychology 26(6): 978-986.

16. Muraven M, Baumeister RF (2000) Self-regulation and depletion of limited resources: Does self-control resemble a muscle? Psychological Bulletin 126(2): 247-259.

17. Muraven M, Slessareva E (2003) Mechanism of selfcontrol failure: Motivation and limited resources. Personality and Social Psychology Bulletin 29(7): 894-906.

18. Muraven M, Shmueli D, Burkley E (2006) Conserving self-control strength. Journal of Personality and Social Psychology 91(3): 524-537.

19. Schmeichel BJ, Vohs KD, Baumeister RF (2003) Intellectual performance and ego depletion: Role of the self in logical reasoning and other information processing. J Pers Soc Psychol 85(1): 33-46.
20. Schmeichel BJ, Vohs K (2009) Self-affirmation and self-control: Affirming core values counteracts ego depletion. J Pers Soc Psychol 96(4): 770-782.

21. Vohs KD, Baumeister RF, Schmeichel BJ, Twenge JM, Nelson NM, et al. (2008) Making choices impairs subsequent self-control: A limited-resource account of decision making, self-regulation, and active initiative. J Pers Soc Psychol 94(5): 883-898.

22. Hagger MS, Wood C, Stiff C, Chatzisarantis NL (2010) Ego depletion and the strengh model of self-control: A meta-analysis. Psychol Bull 136(4): 495-525.

23. Baumeister RF, Tierney J (2011) Willpower: Rediscovering the greatest human strength. New York, NY: The Penguin Press.

24. Honkanen P, Olsen SO, Verplanken B, Tuu HH (2012) Reflective and impulsive influences on unhealthy snacking: the moderating effects of food related selfcontrol. Appetite 58(2): 616-622.

25. Keller C, Hartmann C, Siegrist M (2016) The association between dispositional self-control and longitudinal changes in eating behaviors, diet quality, and BMI. Psychology \& Health 31(11): 1311-1327.

26. Imhoff R, Schmidt AF, Gerstenberg F (2014) Exploring the Interplay of Trait Self-Control and Ego Depletion: Empirical Evidence for Ironic Effects. European Journal of Personality 28(5): 413-424.

27. McClelland DC (1961) The achieving society. New York NY: Free Press.

28. McClelland DC (1965) Toward a theory of motive acquisition. Am Psychol 20: 321-333.

29. McClelland DC, Atkinson JW, Clark RA, Lowell EL (1953) The achievement motive. New York, NY: Appleton-Century-Crofts.

30. Higgins ET (2000) Making a good decision: Value from fit. Am Psychol 55(11): 1217-1230.

31. Higgins ET (1999) Who do self-discrepancies have specific relations to emotions? The second-generation question of Tangney, Niedenthal, Covert, and Barlow (1998). J Pers Soc Psychol 77(6): 1313-1317. 


\section{Psychology \& Psychological Research International Journal}

32. Freitas AL, Higgins ET (2002) Enjoying goal-directed action: The role of regulatory fit. Psychol Sci 13(1): 16.

33. Ryff CD, Keyes CLM (1995) The structure of psychological well-being revisited. J Pers Soc Psychol 69(4): 719-727

34. Seifert TA (2005) The Ryff Scales of Psychological Well-Being. Assessment Notes.

35. Higgins ET, Friedman RS, Harlow RE, Idson LC, Ayduk ON et al. (2001) Achievement orientations from subjective histories of success: promotion pride versus prevention pride. European Journal of Social Psychology 31(1): 3-23.

36. Inglicht M, Schmeichel BJ (2012) What Is Ego Depletion? Toward a Mechanistic Revision of the Resource Model of Self-Control. Perspectives on Psychological Science 7(5): $\quad$ 450-463.

37. Robinson MD, Schmeichel BJ, Inglicht M (2010) A Cognitive control perspective of self-control strength and its depletion. Social and Presonality Psychology Compass 4(3): 189-200.

38. Baumeister RF, Vohs KD (Eds.) (2004) Handbook of self-regulation: Research, theory, and applications. New York, NY: Guilford.
39. Hofmann W, Kotabe H (2012) A general model of preventive and interventive self-control. Social and Personality Psychology Compass 6(10): 707-722.

40. Fujita K (2011) On conceptualizing self-control as more than effortful inhibition of impulses. Personality and Social Psychology Review 15(4): 352-366.

41. Catania JA, Gibson DR, Marin B, Coates TJ, Greenblatt RM (1990) Response bias in assessing sexual behaviours relevant to HIV transmission. Evaluation and Program Planning 13(1): 19-29.

42. Durant LE, Carey MP (2000) Self-Administered Questionnaires versus Face-to-Face Interviews in Assessing Sexual Behaviour in Young Women. Arch Sex Behav 29(4): 309-322.

43. Schroder KEE, Carey MP, Vanable PA (2003) Methodological challenges in research on sexual risk behavior: II. Accuracy of self-reports. Ann Behav Med 26(2): 104-123.

44. Boon B, Stroebe W, Shut H, Ijntema R (2002) Ironic processes in the eating behavior of restrained eaters. Br J Health Psychol 7(1): 1-10. 